Exact Analysis of Structures with Periodicity using U-Transformation 
This page is intentionally left blank 


\title{
Exact Analysis of Structures with Periodicity \\ using U-Transformation
}

\author{
H C Chan \\ University of Hong Kong \\ C W Cai \\ Zhongshan University, China \\ Y K Cheung \\ University of Hong Kong
}


Published by

World Scientific Publishing Co. Pte. Ltd.

P O Box 128, Farrer Road, Singapore 912805

USA office: Suite 1B, 1060 Main Street, River Edge, NJ 07661

UK office: 57 Shelton Street, Covent Garden, London WC2H 9HE

\section{British Library Cataloguing-in-Publication Data}

A catalogue record for this book is available from the British Library.

\section{EXACT ANALYSIS OF STRUCTURES WITH PERIODICITY USING U-TRANSFORMATION}

Copyright $(1) 1998$ by World Scientific Publishing Co. Pte. Ltd.

All rights reserved. This book, or parts thereof, may not be reproduced in any form or by any means, electronic or mechanical, including photocopying, recording or any information storage and retrieval system now known or to be invented, without written permission from the Publisher.

For photocopying of material in this volume, please pay a copying fee through the Copyright Clearance Center, Inc., 222 Rosewood Drive, Danvers, MA 01923, USA. In this case permission to photocopy is not required from the publisher.

ISBN 981-02-3642-5

This book is printed on acid-free paper.

Printed in Singapore by Uto-Print 


\title{
Exact Analysis of Structures with Periodicity Using U-Transformation
}

\author{
H. C. Chan \\ C. W. Cai \\ Y. K. Cheung
}

\section{Authors}

H.C. Chan (CHAN Hon Chuen) is Professor and Head, Department of Civil Engineering at the University of Hong Kong. He received his $\mathrm{Ph} . \mathrm{D}$. from the Imperial College of Science and Technology, University of London in 1965.

C.W. Cai (CAI Chengwu) is Professor in the Department of Mechanics at Zhongshan University, China. He graduated from the Department of Mathematics and Mechanics of Peking University in 1960.

Y.K. Cheung (CHEUNG Yau Kai) is Professor and Pro-ViceChancellor of the University of Hong Kong. He received his Ph.D. and D. Sc. from the University of Wales Swansea in 1964 and 1973 respectively. He was also awarded a D.E. by the University of Adelaide in 1982. 
This page is intentionally left blank 


\section{PREFACE}

This book introduces a new analytical method, U-transformation method, for the exact analysis of structures with periodic property.

In a broad sense, it is fair to say that the U-transformation method is originated from the mode method and yet it is different from the latter. In fact it may be called a mode subspace method. Performing U-transformation on a cyclic periodic structure is equivalent to projecting the displacement vector on the orthogonal mode subspaces in the unitary space. Hence the governing equations for a cyclic periodic structure and the continuity conditions between the substructures could be uncoupled. Consequently the governing equation in the U-space will be turned into $\mathrm{N}$ independent equations in $\mathrm{N}$ subspaces, where $\mathrm{N}$ is the total number of substructures. Besides, the order of the subspace is the same as the degrees of freedom of a single substructure. The difference in the $\mathrm{N}$ problems in the $\mathrm{N}$ subspaces may be reflected by taking a different value in one of the parameters in each subspace. In analytical method, that means the $\mathrm{N}$ governing equations need to be solved only once.

The U-transformation method has many advantages over the mode transformation method. When applying the mode method, it is necessary to work out the mode shapes of the structure. That is a task involving a lot of calculations and computing costs. In the end only numerical solutions would be obtained. In applying the U-transformation method, one can leave out calculating for the mode shapes in a periodic structure. This is because it is possible to give in advance some normalized orthogonal basis for each mode subspace. They form the columns of the U-matrix in the U-transformation. This is the physical background of the uncoupling of the governing equations and the continuity conditions of a periodic structure. For cyclic periodic structures, the U-transformation method has many obvious advantages over the numerical method. When the number of substructures in a periodic structure is altered, it will require a complete re-calculation to obtain a new solution by any numerical method. But with the U-transformation method, it is not necessary to re-analyze the problem again because the number of substructures is merely one of the parameters in the analytical solution. When there is a change in the number of substructures in a periodic structure, the expression of the analytical solution will not change.

By applying the U-transformation method for the analysis of cyclic periodic structures, either analytical approach or numerical approach may be adopted. However, the aim of this book is to illustrate how to obtain analytical solutions. 
This book also provides many practical as well as theoretical exact explicit solutions for a large range of problems. Many of these solutions are new results that have just appeared in international journals for the first time together with some which have not been published before. The reason why the analytical method is used is not only because it will save computation costs, but also because it will enable the relationships between various parameters of the geometrical and physical properties in the problem to be reflected clearly. These relationships will probably often become the bases for optimum design or investigation. It is not a gross overstatement to say that analytical methods still have their great value to justify their existence even in this super-computer age of to-day. The analytical solutions given in this book will serve the following four distinctive purposes if not anything else:

1. It has been demonstrated that the U-transformation method can be applied to obtain exact analytical solutions for periodic structures. These exact analytical solutions could not be easily obtained or have not been obtained by other methods before. This book has illustrated how the U-transformation method can be used to derive the exact solutions for a number of problems of finite and infinite periodic structures under arbitrary static or dynamic loading.

2. With an exact analytical solution for a problem as a reference standard, it is possible to investigate the errors in approximate models for the problem. The analytical solution also gives the relations between the various parameters that contribute towards the errors. Hence it will enable a decision to be made as to under what conditions the approximate model may be acceptable. For instance, a continuous beam on periodic elastic supports may sometimes be simplified as a beam on elastic foundation. As another example, a stiffened plate with equal distance ribs may be treated as an orthotropic plate. This book has given detail analysis and discussions on the errors incurred by employing these two models. An explicit solution has also been given.

3. When a regular uniform continuous structure is sub-divided into a regular equal finite element mesh, for instance, a rectangular plate is sub-divided into a rectangular mesh, the sub-divided mesh may be treated as a periodic structure. That will allow it to be analyzed by the U-transformation method to yield an analytical solution for the finite element equations. Hence, that would facilitate the study of the rate of convergence as well as the convergence of the finite element solution when the number of finite elements approaches infinity. Furthermore, an explicit expression for the main body of the errors may be derived. This could not be achieved with the other methods.

4. It has been demonstrated how to apply the U-transformation method to the analysis of nearly periodic structures. Here only problems containing a few substructures with different properties are discussed and only for the case when 
there is disturbance in the parameters of stiffness and masses. The aim is to study the mode localization phenomena. This phenomenon is very sensitive to the variation of a particular parameter in the sub-structure. It is therefore necessary to obtain a rigorous solution. If an approximate method is employed, it may lead to significant disagreement. It is best to employ analytical methods for this kind of problem.

The first five chapters in this book deal with the fundamental concept and theory of the U-transformation method. In addition to attempting to explain how the U-transformation method can be employed for the analysis of periodic structures, the authors of this book also try to explain how this method may be used in the study of two very important aspects of theoretical mechanics as mentioned in 3 and 4 above. Chapter 6 of this book deals with the exact solution of finite element equation. The chapter also gives an example for the case when the element stiffness matrix contains a stiffness regulative factor. It is possible to adjust the value of the stiffness regulative factor such that the error is minimum so that the rate of convergence may be enhanced. The mode localization is discussed in Chapter 7 . Some solutions and results which have not been solved by using other methods are given in this chapter. These include the conditions that localized mode may occur in one dimension nearly periodic structures, and the theoretical results of the threshold value that causes the localized mode of 3-D nearly periodic structures.

As a mathematical tool, the U-transformation method has now been well systematized. The authors deeply believe that the problems that can be analyzed with the U-transformation method could be far more than those mentioned in this book.

The authors would like to express their sincere gratitude to the University of Hong Kong for providing research grants to support this work and to Professor J.K. Liu and Dr. Y. Li for their assistance in the preparation of this book and typing of the manuscript. While it is not possible to make individual acknowledgment to all the sources of references and materials adopted in this book, it is hoped that full credit is noted through this acknowledgment. Though every effort has been made to ensure exactness and to eliminate errors as far as possible, should errors be found, the authors would greatly appreciate comments and notifications from the learned readers.

H.C. Chan

C.W. Cai

Y.K. Cheung 
This page is intentionally left blank 


\section{CONTENTS}

Preface

1. Uncoupling of the Dynamic Equation for Cyclic Periodic Structures and U-Transformation

1.1 Dynamic Equation 2

1.2 Mode Subspaces of Cyclic Periodic Structures 3

$\begin{array}{lll}1.3 & \text { U-Transformation } & 7\end{array}$

2. Analytical Solutions for Cyclic Periodic Structures 11

2.1 Regular Polygon Frames 11

2.1.1 Static Problem 15

2.1.2 Natural Vibration 17

2.1.3 Forced Vibration 21

2.2 Prism Shells with Regular Polygon Cross Section 23

2.2.1 Natural Vibration $\quad 26$

2.2.2 Buckling Load 30

3. Linear Periodic Structures - Discrete Systems 33

3.1 Periodic Mass-Spring System with Single Degree of Freedom Substructure 33

3.1.1 Periodic Mass-Spring System with Fixed Extreme Ends 33

3.1.2 Periodic Mass-Spring System with Free Extreme Ends 41

3.1.3 Periodic Mass-Spring System with One End Fixed and the Other Free 44

3.2 Periodic Mass-Spring System with Two Degrees of Freedom Substructures

3.3 Transverse Vibration of Plane Trusses 55

3.3.1 Governing Equations $\quad 56$

3.3.2 Static Problem 63

3.3.3 Natural Vibration $\quad 66$

3.3.4 Dynamic Response 69

4. Linear Periodic Structures — Continuous Systems 75

4.1 Continuous Beams - Static Displacements 75

4.1.1 Continuous Beam with Extreme Ends Simply Supported 75 
4.1.2 Continuous Beam with Extreme Ends Clamped

Continuous Beam with One Extreme End Simply Supported and the Other Clamped

4.2 Continuous Beam - Dynamic Analysis $\quad 88$

$\begin{array}{ll}\text { 4.2.1 Natural Vibration } & 90\end{array}$

4.2.2 Dynamic Response 95

4.3 Continuous Beams with Periodic Elastic Supports 104

4.3.1 Static Problem 104

4.3.2 Natural Frequency $\quad 116$

$\begin{array}{ll}4.4 \text { Continuous Deep Beams } & 118\end{array}$

4.4.1 Uniformly Distributed Load 120

4.4.2 Concentrated Load 125

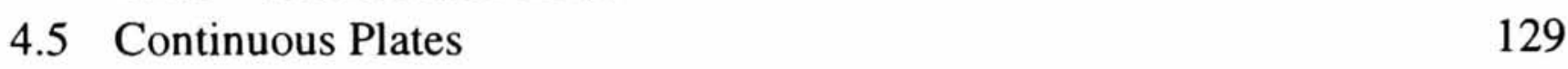

4.5.1 Uniformly Distributed Load 133

4.5.2 Concentrated Load 137

4.6 Stiffened Plates 141

4.6.1 Static Solution of Stiffened Plates 141

4.6.2 Stability Analysis of Stiffened Plates 150

4.6.3 Natural Vibration of Stiffened Plates 161

5. Structures with Periodicity in Two Directions 167

5.1 Governing Equation and Double U-Transformation 167

5.2 Rectangular Orthogonal Networks - Lumped Mass System 173

$\begin{array}{ll}\text { 5.2.1 Dynamic Equation } & 174\end{array}$

$\begin{array}{lll}\text { 5.2.2 Natural Vibration } & 177\end{array}$

$\begin{array}{lll}5.2 .3 & \text { Forced Vibration } & 178\end{array}$

5.3 Rectangular Orthogonal Networks - Continuous System 180

5.3.1 Governing Equation 180

$\begin{array}{lll}\text { 5.3.2 Natural Vibration } & 182\end{array}$

5.3.3 Dynamic Response 189

5.4 Rectangular Diagonal Networks - Lumped Mass System 201

5.5 Rectangular Diagonal Networks - Continuous System 205

$\begin{array}{ll}5.6 \text { Rectangular Grids } & 212\end{array}$

5.6.1 Static Problems 214

5.6.2 Natural Vibration — Lumped Mass System 219

5.6.3 Natural Vibration — Distributed Mass System 222

$\begin{array}{lll}5.7 & \text { Double Layer Grids } & 228\end{array}$

5.7.1 Static Problems 231 
6. Exact Solution of the Finite Element Equation

6.1 Beam Element

6.1.1 Static Problem

6.1.2 Buckling Load

6.1.3 Natural Frequency

6.1.4 Dynamic Response

6.2 Plate Element 264

6.2.1 Static Displacements 268

6.2.2 Buckling Load 271

$\begin{array}{ll}\text { 6.2.3 Natural Frequency } & 277\end{array}$

6.2.4 Dynamic Response 283

$\begin{array}{ll}\text { 7. Nearly Periodic Structures } & 287\end{array}$

$\begin{array}{lll}7.1 & \text { One Dimensional System } & 287\end{array}$

7.1.1 Natural Vibration and Localized Modes 289

$\begin{array}{lll}7.1 .2 & \text { Forced Vibration } & 301\end{array}$

7.2 Two Dimensional System 302

$\begin{array}{lll}7.3 & \text { Three Dimensional System } & 310\end{array}$

Appendix U-Transformation 321

$\begin{array}{lll}\text { A.1 Definitions } & 321\end{array}$

A.2 Property of U Matrix 322

A.3 The Component Forms of U-Transformation and Inverse U-Transformation 